\title{
Technique-related variation in results of FANA tests
}

\author{
PORNTHITA CHAIAMNUAY, CAROL JOHNSTON, JANET MAIER, AND \\ ANTHONY S. RUSSELL
}

From the Division of Rheumatology, 9-112 Clinical Sciences Building, University of Alberta, Edmonton, Alberta, Canada T6G-2G3

SUMMARY We compared the reliability and reproducibility of three tests for fluorescent antinuclear antibodies (FANA) that are routinely performed in our laboratory. Sera from 72 patients, selected according to diagnosis (SLE in 28, RA in 12, and other connective-tissue diseases in 33), and from 32 healthy controls were tested with all three assays. There were wide variations between the results obtained with these tests. The variations did not reflect sensitivity or degree of standardisation (reproducibility on retesting was $>95 \%$ ) and appeared to be inherent in the techniques. Clinicians should be aware of the technique-related differences in FANA assays.

Key words: serodiagnosis, immunological fluorescent antibody techniques, mixed connectivetissue disease, fluorescent antinuclear antibody, lupus erythematosus, systemic.

An indirect assay for fluorescent antinuclear antibodies (FANA) is commonly performed with sera from patients with systemic lupus erythematosus (SLE). When clinically indicated, it is best considered as a sensitive screening test, to be used before methods that are more specific for this disease or for the described disease subsets. Many articles have pointed out that a positive FANA assay is not to be equated with the diagnosis of SLE, and that the population contains more healthy subjects with a positive test than there are diseased.' ${ }^{\prime}$ Nevertheless, the test has an important role, despite the occasional patient with 'ANA negative lupus', and a positive FANA assay has been included in the revised criteria for the diagnosis of SLE. ${ }^{2}$

Recent studies have shown wide variation in FANA results obtained in two laboratories using different techniques. ${ }^{23}$ Other studies ${ }^{4}$ have examined differences in staining pattern or titre with different substrates. We undertook a study to determine whether the simple responses 'positive' or 'negative' varied, and whether this variation was caused by extraneous factors-for example, differences in protocols for freezing and thawing sera, in the antisera, and in their fluorescein:protein ratiosor was inherent in the test and/or substrates. Our laboratory has a continuing interest in antibodies to

Accepted for publication 15 May 1984.

Correspondence to Dr P. Chaiamnuay at above address. nuclear antigens; in addition we routinely perform FANA assays on sera from our own patients and maintain a regular quality control. In this two-part study we first assayed sera from patients and controls with three routine FANA techniques to assess intertest variation, then we repeated the tests with the same techniques to ensure observer consistency and intratechnique reliability.

\section{Materials and methods}

The tests were supervised and performed by our immunology laboratory staff together with a research fellow. Samples were coded, and testing was done without knowledge of the patient's diagnosis or previous results.

Sera. Samples from our serum bank were selected according to diagnosis: 28 from patients who had SLE in various stages of disease activity, 12 from patients with rheumatoid arthritis (RA), and 32 from patients who had other connective tissue disease. In addition we studied sera from 32 healthy subjects. All the samples had been separated into 1 $\mathrm{ml}$ aliquots in plastic vials and had been stored at $-20^{\circ} \mathrm{C}$.

Tissue substrates. (1) Fresh rat liver was flashfrozen in Cryoform and stored at $-20^{\circ} \mathrm{C}$ until used. The tissue was mounted on cryostat blocks; sections were cut $4 \mu \mathrm{m}$ thick and were mounted on gelatin- 
coated glass slides. (2) Human HEp-2 substrate: HEp-2 slides (Kallestad Laboratory, Austin. Texas, USA) were used. (3) FIAX sera was diluted 1/51. and the HEp-2 substrate was examined with FIAX test kits for antinuclear antibodies (International Diagnostic Technology, Santa Clara, California. USA).

For conventional immunofluorescence (substrates 1 and 2) sera were diluted $1 / 15$ and $1 / 30$ for use with goat anti-whole-Ig fluorescein conjugate (Cappel, Cochranville. Pennsylvania, USA). Slides were read with an incident-light Leitz fluorescence microscope. Patterns that were weakly positive $(1+)$ were read as negative. The pattern of staining was noted. If cells or the section had been damaged, the sample was discarded and the serum was resampled for inclusion in a later batch. All slides were read independently by two observers, then compared and agreed before recording. Fifty sera, being roughly half of each diagnosis group and controls, were retested with the three methods for determination of internal reproducibility.

\section{Results}

Table 1 summarises the results for each diagnostic group and controls. In three lupus patients who had consistently negative results, the disease was now in complete remission although they had been seropositive in previous years.

Comparison of the results with the three techniques, with the use of the standard serum dilution $(1 / 15){ }^{+}$showed variation in the results but no indication that any one test was more sensitive than the others (Table 2). When the 50 sera were retested, the results were as on the initial reading except that, with the rat-liver and HEp-2 techniques, the readings were reversed for one sample each $(2 \%$ variation $)$.
Table 2 Comparison of positive and negative results of the three assays of all 104 sera

A. Consistent result with all three assays: positive, 37; negative, 45 ; total: 82 of 104

B. Comparison of results with the assays paired: Number positive with one

method and negative with the other

\begin{tabular}{lll}
\hline RL vs. HEp-2 & RL 9. HEp-2 2 & $\begin{array}{l}\text { both } \\
44\end{array}$ \\
FIAX vs. HEp-2: & FIAX 11. HEp-28 & 38 \\
FIAX vs. RL & FIAX 5. RL 9 & 44
\end{tabular}

\section{Discussion}

No attempt was made to compare titres: if a test is truly being used as a screening test, these are not initially relevant. Moreover, we were primarily concerned with the reliability and consistency of the dogmatic, simple statement of 'positive' or 'negative? The tables are not meant to indicate, for example, the proportion of patients with rheumatoid arthritis who might be expected to have a positive FANA test, for there is considerable prior selection in our referral practice.

HEp-2 cells may demonstrate nuclear staining with antisera to Sjögren`s syndrome B (SSB) antigens, whereas rat liver will not. As it happens. none of the sera we studied had this as its predominant antibody type: the substrates' sensitivity might have been different if sera had been selected for these antibodies. Antibodies to Sjögren's syndrome A SSA are best demonstrated by other techniques.

The specificity of our assay, including the test serum and dilution of the conjugate, had been set so that no more than $3 \%$ of normal sera were expected to give a positive result. We frequently validate this. as well as the reproducibility of given techniques.

Table 1 Results of FANA assays of 104 sera with three techniques

\begin{tabular}{|c|c|c|c|c|c|c|}
\hline \multirow[t]{3}{*}{ No. of sera tested } & & \multicolumn{5}{|c|}{ No. of sera positive } \\
\hline & & \multicolumn{2}{|c|}{ Rat liver } & \multicolumn{2}{|c|}{ Human HEp-2 } & \multirow{2}{*}{$\begin{array}{l}\text { HEp-2 with } \\
\text { FIAX } \\
I / 51\end{array}$} \\
\hline & & $1 / 15$ & $1 / 30$ & $1 / 15$ & $1 / 30$ & \\
\hline Systemic lupus erythematosus & 28 & 24 & 25 & 23 & 24 & 25 \\
\hline Rhcumatoid arthritis & 12 & 7 & 6 & 4 & 4 & 2 \\
\hline Scleroderma & 10 & 8 & 8 & 6 & 7 & 8 \\
\hline \multicolumn{7}{|l|}{ Mixed connective } \\
\hline tissue discase & 6 & 6 & 6 & 6 & 6 & 6 \\
\hline \multicolumn{7}{|l|}{ Other connective } \\
\hline tissuc discase & 16 & 8 & 8 & 6 & 10 & 11 \\
\hline Controls & 32 & 0 & () & 1 & 2 & 0 \\
\hline Total & 104 & 53 & 53 & 46 & 53 & 52 \\
\hline
\end{tabular}


Therefore we were surprised to find such wide variation. The different results obtained with HEp2 and rat-liver substrates may represent true differences in the target tissues, as the other experimental conditions were identical, whereas the different results obtained with the FIAX kit and standard $\mathrm{HEp}-2$ preparations presumably reflect differences in technique and the reagents. The variation does not indicate solely a difference of sensitivity (all three tests gave some negative results with sera that were positive with other techniques) or of reproducibility.

Despite the extent of the intertechnique variation, this may be of less clinical importance than might appear. Thus, of the 34 patients who satisfied the newly revised criteria for SLE (i.e., including six who had mixed connective-tissue disease), three had a consistently negative result on antinuclear antibody testing. Previously when the disease had been active, the test had been strongly positive, but their disease was now in complete remission; this might therefore be taken as a true reading. On rat liver sections the reading was positive for 25 sera at a dilution of $1 / 30$ but for only 24 at a dilution of $1 / 15$. However, when the 25 th sample was retested in the second part of the study to determine internal consistency, this was the serum for which the reading changed to positive and thus may have represented a technical error. On the other hand, one SLE serum positive on rat liver was not detected by the HEp-2 slide tests (Table 1).
As those sera from patients with SLE gave essentially consistent results in all tests, it should not be surprising that this was also found with the WHO international reference ANA standard serum from a patient with active lupus. Thus, overall, where the result of FANA assay is of major clinical importance-that is, in the diagnosis of SLE-all the tests fare relatively well. The variation with other sera serves as a reminder that a positive FANA must not be equated with a diagnosis of SLE.

Dr P. Chaiamnuay is in receipt of an Ogryzlo fellowship from the Arthritis Society. His permanent address is: Section of Rheumatology. Department of Medicine, Pramongkutklao Hospital and the Medical School. Rajvithi Road. Bangkok 4. Thailand.

We are most grateful to Miss U. F. Matthews for her editorial review of the manuscript.

\section{References}

1 Dawkins R L. Peter J B. Laboratory tests in clinical immunology. Am J Med 1980; 68: 3-5.

Am J Med 1980); 68: 3-5.

2 Tan E M. Cohen A S. Fries J F. et al. The 1983 revised criteria for the classification of systemic lupus erythematosus. Arthritis Rheum 1982: 25: 1271-7.

3 Feigenbaum P A. Medsger Jr. T A. Kraines R G. et al. The variability of immunologic laboratory tests. J Rheumatol 1982: 9: $4(1)-14$

4 McCarty G A. Rice J R. Characterization and comparison of commercially available antinuclear antibody kits using single pattern index sera. J Rheumatol 7: 339-47. 